\title{
A developing brain abscess as acute stroke mimic: presentation of case and review of literature
}

\author{
Kristine Prayon¹, Edgardo B. EPE², Anabella A. Salise-Oncog ${ }^{3 *}$ \\ 1 M.D. Purok Morning Star, Brgy. Olingan, Dipolog City, Zamboanga del Norte \\ 2 M.D., Dep.t of Pediatrics, Governor Celestino Gallares Memorial Hospital M. Parras St., Tagbilaran City, Bohol, Philippines 6300 \\ 3 MD, DPPS, FSPCCMP, FPSCCM, Department of Pediatrics, Gov. Celestino Gallares Memorial Hospital, Janssen Heights, Dampas \\ District, Tagbilaran City, Bohol 6300,Philippines
}

*Corresponding Author: Anabella A. Salise-Oncog, MD, DPPS, FSPCCMP, FPSCCM, Department of Pediatrics, Gov. Celestino Gallares Memorial Hospital, Janssen Heights, Dampas District, Tagbilaran City, Bohol 6300, Philippines.

Email: abelle salise@yahoo.com

\section{Abstract}

Whether brain abscess is a cause, or a complication of stroke has been a question that elicited differing opinions. We report a case of a child who initially presented with hemiparesis and seizures. Initial brain tomography did not show hemorrhage or infarction. He was managed as a case of childhood stroke. The neurologic manifestations gradually improved until the $17^{\text {th }}$ day of hospitalization when regression of the motor strength and anisocoria occurred. A repeat brain tomography showed multiple masses and vasogenic edema consistent with brain abscess.

Keywords: Brain abscess, Acute stroke, Brain tomography.

\section{INTRODUCTION}

It has been a long-standing debate whether a brain abscess is a complication of stroke or is a cause of stroke-like manifestations. Majority of case reports on brain abscess either as a complication of stroke, or as a stroke mimic are in adults. Here, we present a case of a brain abscess in a child who presented with stroke.

\section{CASE REPORT}

We report the case of a 12-year old boy who was admitted to our institution for sudden onset of right-sided weakness. Four days prior to admission he started to have low to moderate grade intermittent fever associated with occasional nonparoxysmal unproductive cough. He was prescribed with Clarithromycin, antihistamine, and B2-agonist medications, with resolution of symptoms. The fever recurred 1 day prior to admission associated with 2 episodes of nonprojectile vomiting of previously ingested food, and a throbbing frontal mild to moderate headache. About 12 hours prior to admission, the patient could no longer move his right upper and lower extremities, prompting transport to the hospital where he had an episode of generalized tonic clonic seizures lasting for 10 seconds.
The past medical history revealed that the patient had a bout of fever and cough about 3 weeks prior to admission, for which he was prescribed Amoxicillin-clavulanic and Salbutamol, with subsequent improvement.

In the emergency room, the patient was examined conscious, coherent, oriented to 3 spheres, verbal but unable to move his right upper and lower extremities, and febrile at $38.6^{\circ} \mathrm{C}$. The systemic physical examination findings were generally normal. However, the neurologic examination revealed a flattened right nasolabial fold, inability to lift his right shoulder, and deviation of the tongue to the right on protrusion. There was $0 / 5$ motor strength of the right upper and lower extremities. Babinski sign present at the right. Hyporeflexia was noted on the right upper and lower extremities.

The patient was initially admitted as childhood stroke, and was worked up along this impression. There was neutrophilia seen in the complete blood count. This, together with the fever prompted administration of antibiotics. Hyponatremia at 127.5 $\mathrm{mEq} / \mathrm{L}$ was seen. The prothrombin time was prolonged with an activity of $57.4 \%$ while the activated partial thromboplastin time was normal. The lipid profile showed low high density lipoproteins (HDL). The urinalysis was normal. The chest radiograph and the 2-dimensional echocardiography were normal. 
The initial non-contrast cranial CT scan only showed focal brain atropy at the right frontal lobe area without any sign of hemorrhage or infarction.

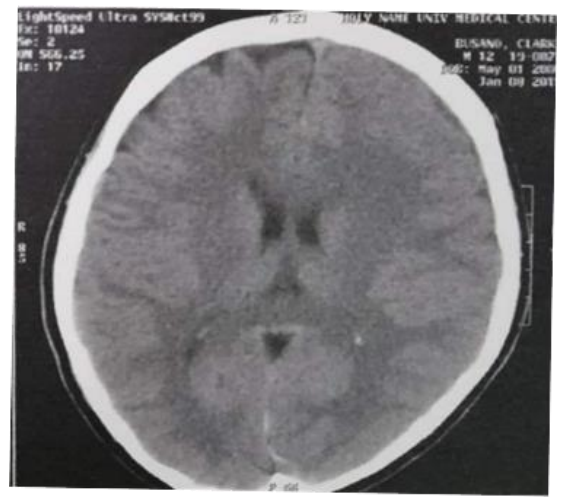

The fever resolved on the third day of hospitalization while on the antibiotics, but the motor deficits did not improve. Physical therapy was started.

By the sixth day of hospitalization, the patient's motor strength on the right upper and lower extremity was seen to be $2 / 5$, which further improved to $3 / 5$ the next day. Rehabilitation therapy and the antibiotics were continued.

The patient's condition was progressively improving, when on the $17^{\text {th }}$ hospital day there was note of sudden regression of the motor strength of the affected side to $0 / 5$. Anisocoria was also noted. A re-stroke was considered so a repeat noncontrast brain CT scan was performed; this time, multiple defined masses on the left frontal lobe were seen with vasogenic edema and mass effect, consistent with a brain abscess.

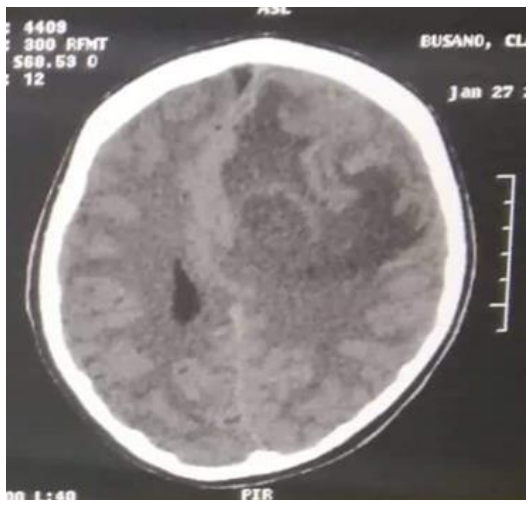

A neurosurgery referral was made, and a contrast-enhanced brain CT scan was proceeded, revealing multiple enhancing complex masses, with subfalcine herniation to the right.

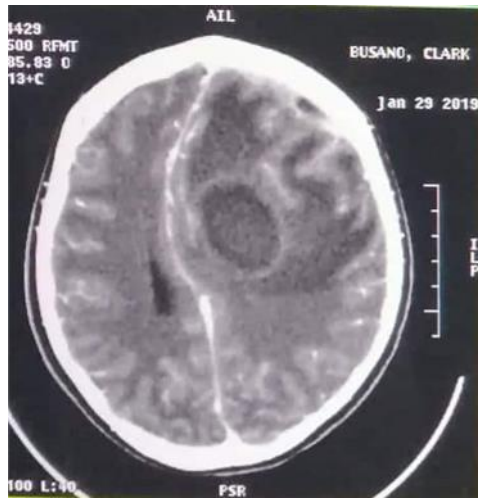

Medical and surgical decompression was done. Antibiotics were shifted to Metronidazole, Amikacin, and Meropenem per brain abscess guidelines. Post-operatively, the patient's pupils became isocoric, the motor strength in the right lower extremity was $1 / 5$ while the motor strength in the right upper extremity was $0 / 5$.

With the medications and rehabilitation, his condition gradually improved. By the $8^{\text {th }}$ postop day, he was already able to gain full motor strength in the right leg while the right arm strength improved to $2 / 5$.

A repeat contrast-enhanced cranial CT scan done on the $37^{\text {th }}$ hospital day showed interval enlargement of the rim-enhancing fluid density in the left frontal lobe, surrounding vasogenic edema and expansile effect, right subfalcine herniation and left frontal craniotomy defect.

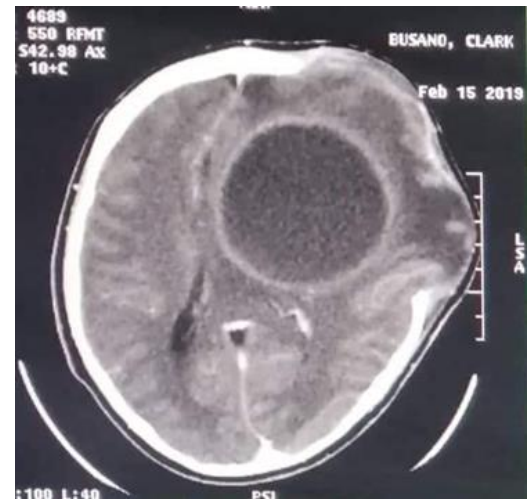

Aspiration of the abscess was performed. Culture of the abscess fluid did not yield any growth. Antibiotics were continued.

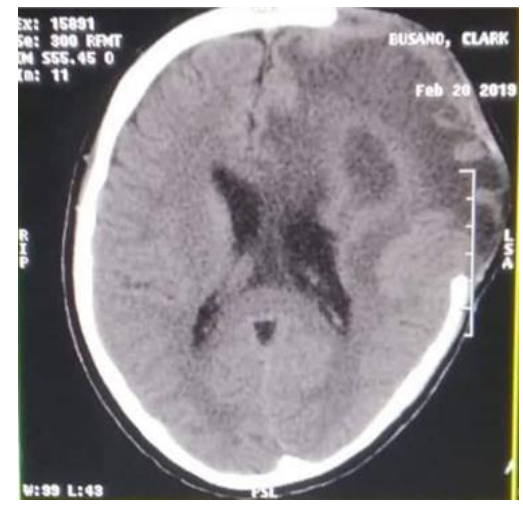

A repeat cranial CT scan on the $42^{\text {nd }}$ hospital day showed interval decrease in size of rim-enhancing fluid density in the left frontal lobe and interval decrease in rightward subfalcine herniation, still with vasogenic edema. Medications were continued and further clinical improvement was noted.

Patient was discharged on the $45^{\text {th }}$ hospital day already isocoric, with full strength in both lower extremities and left upper extremity, and residual weakness in the right upper extremity.

\section{DISCUSSION}

Childhood stroke is defined similarly as adult stroke: an acute onset neurological sign or symptom attributable to a focal brain infarction or hemorrhage ${ }^{[1,2]}$. Just like in adults, childhood stroke can be divided into hemorrhagic and ischemic stroke. Hemorrhagic stroke may be intraparenchymal or spontaneous nontraumatic subarachnoid hemorrhage. Focal brain damage results from hemorrhage through localized mass effect and 
ischemia of adjacent tissues. Cerebral infarction or ischemic stroke may result from arterial ischemic stroke (AIS), venous infarction, or cerebral sinovenous thrombosis (CSVT). Focal brain damage from ischemic stroke results when there is a loss of blood flow or oxygenation to an area of brain tissue [3].

Stroke in children is reported to be common. It affects 1 in 1,600 $-4,000$ neonates ${ }^{[3,4]}$, and 2.3 to 13 per 100,000 older children annually $[5,6,7]$. Hemorrhagic stroke accounts for $50 \%$ of pediatric stroke, with an annual incidence of approximately $1-1.7$ in 100,000 children ${ }^{[6,8]}$. The remaining $50 \%$ of pediatric stroke is accounted for by ischemic stroke, with a slightly higher annual incidence of $1-2$ per 100,000 children in developed countries $[8,9]$. In the Philippines, the registry of childhood diseases of the Philippine Pediatric Society, Inc., shows that there is a total of 701 reported cases of stroke in children from January 1, 2006 to December 31, 2019 [10]. In a country with roughly 42,311,222 children [11], the annual incidence rate of stroke is approximately 0.12 per 100,000 Filipino children. This number is much lower than that was reported for developed Western countries. However, this may not be a true reflection of the incidence of stroke among Filipino children as the PPS registry collects data only from their accredited training hospitals.

The most common symptoms of acute stroke in children are similar to those in adults. These include hemiparesis and hemifacial weakness (67 - 90\%), speech or language disturbance $(20-50 \%)$, vision disturbance $(10-15 \%)$, and ataxia $(8-10 \%)$. Nonlocalizing symptoms like headache and altered mental status may also be present. Seizures manifest in 15 to $25 \%$ of children with stroke ${ }^{[12-15]}$. Seizure serves as a sentinel sign of acute stroke in children, occurring in $31 \%$ to $46 \%$ of younger children with stroke ${ }^{[3]}$. Our patient presented with headache, vomiting, right-sided hemiparesis, and seizures. Clearly, our patient's clinical manifestations are compatible with acute stroke.

The nature of the stroke-like manifestations of the patient on presentation was a dilemma for a time because aside from the absence of an infarcted area in the brain on the initial cranial CT scan, the search for the more common etiologies like sickle cell disease, cardiac disorders, or prothrombotic conditions were negative. A suspicion for yet undetermined infection was considered based on the presence of fever and neutrophilia in the complete blood count.

Literatures show that only approximately $50 \%$ of patients with ischemic stroke will have known risk factors predisposing to stroke at the time of diagnosis. However, after thorough evaluation, $40 \%$ of children with ischemic stroke are found to have 1 risk factor, $50 \%$ have 2 or more factors, and $10 \%$ have no identified risk factor for stroke. These risk factors include arteriopathies, cardiac disorders, infection, acute head and neck disorders, acute systemic conditions, chronic systemic conditions, prothrombic states, chronic head and neck disorders, atherosclerosis-related risk factors, and others ${ }^{[16]}$.

The pathophysiology of the stroke in our patient was made clearer when a repeat cranial tomography showed multiple defined masses on the left frontal lobe with vasogenic edema and mass effect, which showed enhancement with contrast. This finding was compatible with brain abscess.

Brain abscess is a focal infection in the brain parenchyma consisting of encapsulated pus and pyogenic bacteria. Less commonly, fungi, mycobacteria or protozoa cause brain abscess [17]. Brain abscesses are reportedly rare in children, but they can cause significant morbidity and mortality [18]. They occur in 0.4 per 100,000 children annually but may range from 0.3 to $1.3 \mathrm{per}$
100,000 children ${ }^{[17]}$. The registry of childhood diseases of the Philippine Pediatric Society (PPS), Inc. shows that there are 1,206 cases of intracranial abscess over 14 years [10]. This translates to an annual incidence of 0.20 per 100,000 Filipino children. This number is lower than the reported incidence and contrasts with the report by Gaskill and Marlin in 2008 which said that there is a higher incidence of brain abscess in underdeveloped countries [20]. They more common in males in the first two decades of life ${ }^{[21]}$. Children 4 to 7 years old have the highest incidence of brain abscess [19, 22]. The locations of abscesses in the brain, in decreasing frequency, are frontotemporal, frontoparietal, parietal, cerebellar, and occipital areas [23].

Eighty percent of children with brain abscess have predisposing factors while $20 \%$ of cases are cryptogenic ${ }^{[17]}$. Among children with predisposing factors, $30-50 \%$ result from contiguous focus of infection like otitis media, mastoiditis, sinusitis, orbital cellulitis [17], or dental infections [24]. Approximately $10 \%$ of cases occur in cases where the body's natural barriers are disrupted like in cases of neurosurgical procedures or head trauma [17, 25, 26]. Hematogenous spread associated with bacteremia and immunosuppressive conditions accounts for $40 \%$ of cases of brain abscess in children ${ }^{[17]}$. Direct spread of the organism from a contiguous focus of infection usually causes solitary brain abscess ${ }^{[24]}$ while bacteremic spread typically causes multiple brain abscesses ${ }^{[27]}$. Based on the history and the physical exam which did not show evidence of probable contiguous foci of infection, neurosurgical procedure or head trauma, and the multiple abscess lesions seen in the cranial tomogram, the brain abscesses in our patient must have resulted from a bacteremic route. However, despite work-up, there was no underlying condition that was identified. This absence of an underlying condition or a primary site of infection has been reported in $20-$ $40 \%$ of patients with brain abscess.

The signs and symptoms of brain abscess are initially nonspecific $[28,31]$. Headache is the most common symptom, occurring in $69 \%$ of cases. Fever occurs in $45-53 \%$ of patients, seizures in $25 \%$, and focal neurologic deficits in up to $50 \%$ of children with brain abscess [32,33]. Individually, each of these signs and symptoms is not a reliable basis for the diagnosis of brain abscess. Even the classic triad of fever, headache, and focal neurologic deficits that suggests brain abscess is present in only $20 \%$ of cases ${ }^{[34]}$. Thus, a high index of suspicion is recommended. Our patient presented with fever, headache, and hemiparesis. This should have alerted us to the possibility of brain abscess on admission; however, in the absence of abscess lesions on the initial cranial tomogram, the diagnosis of brain abscess was not considered on admission.

Hemiparesis in cases of brain abscess is reported to be more common in children than in adults. In a review of literatures on brain abscesses in children, the incidence of hemiparesis ranged from $19.2 \%$ to $44.06 \%[35,36,37]$. This high incidence was demonstrated to result from the involvement of the eloquent areas of the brain with seeding of metastatic abscesses ${ }^{[37]}$.

The question that we asked ourselves in the management of this patient was that is this a case of the brain abscess being a stroke mimic or is the brain abscess a complication of stroke. Unfortunately, there is a dearth of literatures related to this topic in pediatrics. However, there have been reports of brain abscess as complication of stroke in adults. To date, there are 20 case reports of brain abscess after stroke that were published [38-57]. All of these are reported in adults. The abscess is reported to develop 12 days to 14 months after the stroke incident ${ }^{[58,59]}$. Our patient was diagnosed with brain abscess 17 days after the stroke. 
The pathogenesis of brain abscess after a stroke involves the disruption and loss of integrity of the blood brain barrier around the ischemic area ${ }^{[43]}$, making it vulnerable to microbial seeding when bacteremia occurs during a systemic infection [38].

However, brain abscess as a complication of the ischemic stroke could not be explained by the afebrile state of our patient at the time of or immediately before the diagnosis of brain abscess was made. This made us consider an alternative scenario where the developing brain abscess acted as a stroke mimic.

There have also been reports of brain abscesses as stroke mimics [60-70]. Unfortunately again all these reports are in adults. The exact mechanism how a brain abscess presents with strokelike symptoms is still unclear. One hypothesis is the development of paroxysmal septic emboli that causes embolic infarction which becomes the nidus for the abscess formation ${ }^{[61]}$. However, the septic work-up in our patient did not reveal any focus of infection that could have thrown a septic embolus to the brain. The authors hypothesize that the stroke-like manifestations in our patient, not accompanied by an apparent infarct in the cranial tomogram, may be due to the cerebritis stage of abscess formation and its accompanying inflammatory vasculitis or in-situ thrombus formation, and that the brain abscess in our patient could have been cryptogenic in nature. It has been reported that the cranial tomography of the brain may be negative or may show only subtle nonspecific findings during the early stages of evolution of a brain abscess ${ }^{[71]}$. It could have been better if a magnetic resonance imaging of the brain was done as it is the preferred imaging method in the initial examination. Sadly, our institution lacks this technology for now.

The most important lesson that this patient taught us, regardless of whether the brain abscess is a complication of a stroke or is a stroke mimic, is that a high index of suspicion for the possibility of a brain abscess in a patient with stroke-like manifestations is quite necessary for early diagnosis and treatment to prevent significant morbidity and mortality.

\section{REFERENCES}

1. Grinnon ST, Miller K, Marler JR, Lu Y, Stout A, Odenkirchen J, Kunitz S. National Institute of Neurological Disorders and Stroke Common Data Element Project: approach and methods. Clin Trials, 2012; 9:322-329.

2. Sacco RL, Kasner SE, Broderick JP, Caplan LR, Connors JJ, Culebras A, et al. On behalf of the American Heart Association Stroke Council, Council on Cardiovascular Surgery and Anesthesia, Council on Cardiovascular Radiology and Intervention, Council on Cardiovascular and Stroke Nursing, Council on Epidemiology and Prevention, Council on Peripheral Vascular Disease, and Council on Nutrition, Physical Activity and Metabolism. An updated definition of stroke for the $21^{\text {st }}$ century: a statement for healthcare professionals from the American Heart Association/American Stroke Association. Stroke, 2013; 44:20642089.

3. Bernson-Leung ME, Rivkin MJ. Stroke in neonates and children. Pediatrics in Review, 2016; 37(11):463-477. DOI: 10.1542/pir.2016-0002.

4. Laugesaar R, Kolk A, Tomberg T, Metsvaht T, Lintrop M, Varendi $\mathrm{H}$, Talvik T. Acutely and retrospectively diagnosed perinatal stroke: a population-based study. Stroke, 2007; 38(8):2234-2240.

5. Giroud M, Lemesle M, Gouyon JB, Nivelon JL, Milan C, Dumas R. Cerebrovascular disease in children under 16 years of age in the city of Dijon, France: a study of incidence and clinical features from 1985 to 1993. J Clin Epidemiol, 1995; 48(11):1343-1348.

6. Fullerton $\mathrm{HJ}, \mathrm{Wu}$ YW, Zhao S, Johnston SC. Risk of stroke in children: ethnic and gender disparities. Neurology, 2003; 61(2):189-194.

7. Agrawal N, Johnston SC, Wu YW, Sidney S, Fullerton HJ. Imaging data reveal a higher pediatric stroke incidence than prior US estimates. Stroke, 2009; 40(11):3415-3421.
8. Lehman LL, Khoury JC, Taylor JM, Yeramaneni S, Sucharew H, Alwell K, et al. Pediatric stroke rates over 17 years: report from a population-based study. J Child Neurol, 2018; 33(7):463-467.

9. Ferriero DM, Fullerton HJ, Bernard TJ, Billinghurst L, Daniels SR, DeBaun MR, et al. On behalf of the American Heart Association Stroke Council and Council on Cardiovascular and Stroke Nursing. Management of stroke in neonates and children: a scientific statement from the American Heart Association/American Stroke Association. Stroke, 2019; 50(3):e51-e96.

10. Philippine Pediatric Society (PPS), Inc. (2020). Data search. Retrieved from https://pps.ivant.com/search.do.

11. Philippine Statistics Authority. Philippine population surpassed the 100 million mark (results from the 2015 census of population), 2017. Retrieved from https://psa.gov.ph/population-andhousing/node/ 120080

12. Steinlin M, Pfister I, Pavlovic J, Everts R, Boltshauser E, Capone Mori A, et al, Swiss Societies of Paediatric Neurology and Neonatology. The first three years of the Swiss Neuropaediatric Stroke Registry (SNPSR): a population-based study of incidence, symptoms and risk factors. Neuropediatrics, 2005; 36:90-97.

13. Christerson S, Strömberg B. Childhood stroke in Sweden I: incidence, symptoms, risk factors and short-term outcome. Acta Paediatr, 2010; 99(11):1641-1649.

14. Mallick AA, Ganesan V, Kirkham FJ, Fallon P, Hedderly T, McShane $T$, et al. Childhood arterial ischaemic stroke incidence, presenting features, and risk factors: a prospective populationbased study. Lancet Neurol, 2014; 13(1):35-43.

15. Yock-Corrales A, Mackay MT, Mosely I, Maixner W, Babl FE. Acute childhood arterial ischemic and hemorrhagic stroke in the emergency department. Ann Emerg Med, 2011; 58(2):156-163.

16. Mackay MT, Wiznitzer M, Benedict SL, Lee KJ, Deveber GA, Ganesan V. International Pediatric Stroke Study Group. Arterial ischemic stroke risk factors: the International Pediatric Stroke Study. Ann Neurol, 2011; 69(1):130-140.

17. Weinberg GA. Brain abscess. Pediatrics in Review, 2018; 39(5):270-272.

18. Mameli C, Genoni T, Madia C, Doneda C, Penagini F, Zuccotti G. Brain abscess in pediatric age: a review. Childs Nerv Syst, 2019; 35(7):1117-1128

19. Frazier JL, Ahn ES, Jallo GI. Management of brain abscesses in children. Neurosurg Focus, 2008; 24(6):E8.

20. Gaskill SJ, Marlin AE. Brain abscesses and encephalitis. In A. L. Albright, I. F. Pollack, \& P. D. Adelson (Eds.), Principles and practice of pediatric neurosurgery (2 ${ }^{\text {nd }}$ edition) (pp. 1162-1181), Thieme Publishers New York, 2008.

21. Osenbach RK, Haines SJ. Infections in neurological surgery. In A. J. Moore, \& D. W. Newell (Eds.), Neurosurgery principles and practice (pp. 631-637), Springer-Verlag London, 2005.

22. Kaplan D. Brain abscess. Med Clin North Am, 1985; 69:345-360.

23. Nielsen H, Gyldensted C, Harmsen A. Cerebral abscess. Aetiology and pathogenesis, symptoms, diagnosis and treatment. A review of 200 cases from 1935-1976. Acta Neurol Scand, 1982; 65(6):609-622.

24. Southwick FS. Pathogenesis, clinical manifestations, and diagnosis of brain abscess, 2020. Retrieved from https://www.uptodate.com/contents/pathogenesis-clinicalmanifestations-and-diagnosis-of-brain-abscess

25. Lew JF, Wiedermann BL, Sneed J, Campos J, McCullough D. Aerotolerant Clostridium tertium brain abscess following a lawn dart injury. J Clin Microbiol, 1990; 28(9):2127.

26. Foy $P$, Sharr M. Cerebral abscesses in children after pencil-tip injuries. Lancet, 1980; 2(8196):662.

27. Bakshi R, Wright PD, Kinkel PR, Bates VE, Mechtler LL, Kamran $\mathrm{S}$, et al. Cranial magnetic resonance imaging findings in bacterial endocarditis: the neuroimaging spectrum of septic brain embolization demonstrated in twelve patients. J Neuroimaging, 1999; 9(2):78.

28. Schliamser SE, Bäckman K, Norrby SR. Intracranial abscesses in adults: an analysis of 54 consecutive cases. Scand J Infect Dis, 1988; 20(1):1.

29. Ng PY, Seow WT, Ong PL. Brain abscesses: review of 30 cases treated with surgery. Aust N Z J Surg, 1995; 65(9):664.

30. Yang SY, Zhao CS. Review of 140 patients with brain abscess. Surg Neurol, 1993; 39(4):290.

31. Chalstrey S, Pfleiderer AG, Moffat DA. Persisting incidence and mortality of sinogenic cerebral abscess: a continuing reflection of 
late clinical diagnosis. J R Soc Med, 1991; 84(4):193.

32. Brouwer MC, Coutinho JM, van de Beek D. Clinical characteristics and outcome of brain abscess: systematic review and metaanalysis. Neurology, 2014; 82(9):806.

33. Seydoux C, Francioli P. Bacterial brain abscesses: factors influencing mortality and sequelae. Clin Infect Dis, 1992; 15(3):394.

34. Sonneville R, Ruimy R, Benzonana N, Riffaud L, Carsin A, Tadié JM, et al. ESCMID Study Group for Infectious Diseases of the Brain (ESGIB). An update on bacterial brain abscess in immunocompetent patients. Clin Microbiol Infect, 2017; 23(9):614.

35. Tekkök IH, Erbengi A. Management of brain abscess in children: review of 130 cases over a period of 21 years. Child's Nerv Syst, 1992; 8(7):411-416.

36. Wong TT, Lee LS, Wang HS, Shen EY, Jaw WC, Chiang CH, et al. Brain abscesses in children - a cooperative study of 83 cases. Child's Nerv Syst, 1989; 5(1):19-24.

37. Ciurea AV, Stoica F, Vasilescu G, Nuteanu L. Neurosurgical management of brain abscesses in children. Child's Nerv Syst, 1999; 15:309-317.

38. Chen ST, Tang LM, Ro LS. Brain abscess as a complication of stroke. Stroke, 1995; 26(4):696-698.

39. Kraemer JL, Worm PV, de Barros Faria M, Maulaz A. Brain abscess following ischemic stroke with secondary hemorrhage. Arq Neuropsiquiatr, 2008; 66(1):104-106.

40. Wang J, Fraser JF. An intracranial petri dish? Formation of abscess in prior large stroke after decompressive hemicraniectomy. World Neurosurg, 2015; 84(5):1495e51495.e9.

41. Dashti SR, Baharvahdat H, Sauvageau E, Chang SW, Stiefel MF, Park MS, et al. Brain abscess formation at the site of intracerebra hemorrhage secondary to central nervous system vasculitis. Neurosurg Focus, 2008; 24(6):E12.

42. Rigante L, Tulfo T Scoppettuolo G, Donato C, Mangiola A. Brain abscess developing in a non-operated spontaneous intracerebral haemorrhage: a case report and literature review. Turk Neurosurg, 2013; 23(6):835-839.

43. Yamanaka K, Ishihara M, Nakajima S, Yamasaki M, Yoshimine T. Brain abscess following intra-arterial thrombolytic treatment for acute brain ischemia. J Clin Neurosci, 2011; 18(7):968-970.

44. Okami N, Kawamata T, Sasahara A, Yamasato M, Kawamura $\mathrm{H}$. [Brain abscess following thalamic hemorrhage: a case report]. No Shinkei Geka, 2000; 28(3):275-279.

45. Thomas SG, Moorthy RK, Rajshekhar V. Brain abscess in a nonpenetrating traumatic intracerebral hematoma: case report and review of literature. Neurol India, 2009; 57(1):73-75.

46. Mason SE, Dueker ND, Stratton CW, Whetsell WO Jr. An 80-year old man with a ring-enhancing right basal ganglia lesion. Brain Pathol, 2008; 18:288-291.

47. Emmez H, Börcek AO, Dogulu F, Ceviker N. Ischemic stroke complicated by a brain abscess: a case report and review of literature. Turk Neurosurg, 2007; 17(1):48-54.

48. Sumioka S, Kajikawa H, Yamamura K, Furuse M, Kajikawa M, Pant B. [Putaminal abscess occurring at the site of hemorrhage: a case report]. No Shinkei Geka, 1996; 24(9):859-863.

49. Pachiyappan JT, Kunjithapatham D, Chinnamuthu S, Yellapragada P. Asymptomatic massive cerebral abscess following malignant cerebral infarct - aggressive surgery - Ray of Hope. Indian J Neurosurg, 2018; 7:269-271.

50. Xue W, Wang Z. One case report of intracerebral abscess after cerebral infarction. Chin J Neurosurg Dis Res, 2005; 4:373.

51. Jung SH, Lee SJ, Byun SY, Jung MG, Kim HL, Choi JH, et al. [Brain abscess developed on the lesion site of previous ischemic stroke]. J Korean Neurol Assoc, 2010; 28(1):33-35.

52. Rao SK, Ahmad O, Tariq F, Suchdev K, Mittal S, Mohamed W. Cerebral abscess following mechanical thrombectomy for ischemic stroke: report of a case and review of literature. Cureus, 2018; 10(6):e2824.

53. Nakai K, Yamamoto T, Yasuda S, Matsumura A. Brain abscess following intracerebral haemorrhage. J Clin Neurosci, 2006; 13(10):1047-1051.

54. Liu K, Yang C, Zhang Y, Yuan X, Xiao H, Bai Y, Xi B. Brain abscess following intracerebral hemorrhage in a patient with pneumonia. J Craniofac Surg, 2016; 27(8):e773-e775.

55. Siatouni A, Mpouras T, Boviatsis EJ, Gatzonis S, Stefanatou M, Sakas D. Brain abscess following intracerebral haemorrhage. J Clin Neurosci, 2007; 14(10):986-989.
56. Amonn F, Müller U. [Brain abscess - a possible complication of cerebral infarction?]. Schweiz Med Wochenschr, 1984; 114(2):5862.

57. Beloosesky Y, Streifler JY, Eynan N, Grinblat J. Brain abscess complicating cerebral infarct. Age Ageing, 2002; 31(6):477-480.

58. Arentoft H, Schønheyder H, Schønemann NK. Cerebral Salmonella typhimurium abscess in a patient with a stroke. Infection, 1993; 21(4):251-253.

59. Miyazaki H, Ito S, Nitta $\mathrm{Y}$, lino N, Shiokawa Y. Brain abscess following cerebral infarction. Acta Neurochir (Wien), 2004; 146(5):531-532.

60. Bagga V, Simmons MA. Cerebral abscesses - a stroke mimic. Age and Ageing, 2011; 40(5):645.

61. Mori K, Miwa K, Hara S, Nakashima T, Ueda T, Yokoyama K, Sakai N. [A case of a bacterial brain abscess presenting as symptoms of 'sudden stroke-like' onset]. No Shinkei Geka, 2003; $31: 443-448$

62. Thomas L, Sama P, Cragun H. Nocardial brain abscess mimicking stroke in a patient with Wegener's granulomatosis and hypothyroidism. Southern Medical J, 2004; 97(10):S57.

63. Lavalard E, Guillard T, Baumard S, Grillon A, Brasme L, Rodriguez-Nava V, et al. [Brain abscess due to Nocardia cyriacigeorgica simulating an ischemic stroke]. Annales de Biologie Clinique, 2013; 71(3):345-348.

64. Schiff J, Maslak G, Zeineddine N, Rosenzweig J. A case of Nocardia farcinica presenting as aphasia in immunocompetent host, 2019. Retrieved from https://www.contagionlive.com/publications/contagion/2019/augu st/a-case-of-cns-nocardia-farcinica-presenting-as-aphasia-in-animmunocompetent-host.

65. Börm W, Gleixner M. Nocardia brain abscess misinterpreted as cerebral infarction. J Clin Neurosci, 2003; 10(1):130-132.

66. Braun EM, Nemetz U, Bachna-Rotter S, Walch C. Otogenic brain abscess mimicking as stroke. Otology \& Neurology, 2015; 36(7):e117-e118.

67. Tsifi A, Lontou SP, Triantafyllou M, Chatzidavid S, Theodoridis D, Skouloudi M, Mantzourani M. Listeria monocytogenes brain abscess mimicking ischemic stroke in an immunocompromised patient: a case report. CMI, 2019; 13(1):23-28.

68. Matuja SS, Khanbhai K, Mahawish KM, Munseri P. Stroke mimics in patients clinically diagnosed with stroke at a tertiary teaching hospital in Tanzania: a prospective cohort study. BMC Neurol, 2020; 20:270. https://doi.org/10.1186/s12883-020-01853-7.

69. Rother J. (n. d.) Stroke-mimicking conditions. Retrieved from http://eknygos.Ismuni.lt/springer/264/285-291.pdf.

70. Jeong DE, Lee J. Brain abscess masquerading as brain infarction. Brain Sci, 2019; 10:440. doi: 10.3390/brainsci10070440.

71. Nadalo LA. Brain abscess imaging, 2017. Retrieved from https://emedicine.medscape.com/article/336829-overview. 